\title{
AUSTRALIAN CARABID BEETLES I. SOME CLIVINA FROM WESTERN AUSTRALIA ${ }^{1}$
}

By P. J. DARLINGTON JR.

Museum of Comparative Zoology, Harvard University

This is the first of what I hope will be a long series of papers on Australian Carabidae. The papers will be based chiefly on the collection of the Museum of Comparative Zoology. The Museum possesses much material secured in Australia, especially in eastern and southwestern districts, by myself and other members of the Harvard Australian Expedition of 1931-1932; some collected by myself in South Queensland in October and November 1943, while I was staging with the 26th Malaria Survey Unit of the Army of the United States; and sets of duplicates from the South Australian Museum, the National Museum at Melbourne, and from several private collectors; and recently we have received additional interesting specimens from many localities in Australia collected in 1950-1951 by Dr. W. L. Brown, now Assistant Curator of Insects at the M. C. Z. I plan to work up appropriate portions of this material in connection with study of large collections of New Guinean Carabidae secured during the war. The present paper concerns certain interesting Western Australian species of the nearly cosmopolitan genus Clivina.

My intention in this series of papers is, so far as possible, to describe only those new species which are well defined and of which we have more than one specimen, and to return at least one of the type series of each new form to Australia. I am particularly anxious that a good set of specimens be deposited at Canberra, with the collection of the late Thomas G. Sloane, who did so much fine work on Australian Carabidae.

The papers of this series are to be regarded as preliminary to more extensive work which I plan to do on Aus-

3 Published with a grant from the Museum of Comparative Zoology at Harvard College. 
tralian Carabidae after (I hope) another collecting trip to Australia and accumulation of much more material. The later work is planned to take the form of revisions with comparative illustrations. Since I cannot foresee the exact forms of illustration which will prove most useful in different groups, I do not plan to illustrate the present preliminary series.

All statements of proportions, $e . g$. the relative widths of head and prothorax, in my descriptions are based upon actual measurements made with a ruled ocular in a binocular microscope. It is not possible to estimate proportions accurately without measuring. Width of head includes the eyes; width of prothorax is greatest width; length of prothorax, length at middle including margins, but not including advanced anterior angles or the peduncle; width of elytra is greatest width; length of elytra, length from a transverse line tangent to the base to apex at suture, with the specimen in normal, flat position.

Sloane's revision of Australian Clivina appeared in 1896; his supplementary revision of certain groups, in 1904; and additional descriptions in 1896, 1907, 1916, 1917, and 1923 (see references). These papers lay the groundwork for classification of the Australian species of the genus, but much detailed work remains to be done. There is hardly a species which does not need to be redescribed and figured and its variations studied. Two characters deserve special mention here, one because it has been overstressed by Sloane, the other because it has not been noticed enough. The transverse impression of the declivity of the prosternal process is not a trustworthy taxonomic character; the impression is sometimes both present and absent in different specimens of series of single species from single localities. The inner or flying wings, supposed by Sloane $(1896$, p. 145) always to be present in Australian Clivina, are actually vestigial in some of the species, including one of the new ones described below. Dimorphism of inner wings may occur too, but has not yet been demonstrated in any Australian species of Clivina.

The new species of Clivina here described have been checked not only against the collection of the Museum of 
Comparative Zoology and the literature, but against the collection of the British Museum, which contains Blackburn's types and specimens identified by Sloane. The present new species all go into Clivina in the strict sense in Kult's classification (Acta Soc. Ent. Čechosl. [Czecholovakia] XLIV, 1947, 26-37).

Clivina frenchi Sloane (1896, p. 159)

Previously known from North Queensland and from Lake Callabonna, South Australia. I took a series of specimens, which agree exactly with the description, near WiLuNA, interior of Western Australia, September 28 to October 3,1931 , some on the shores of Lake Violet (near Lake Way) and others beside water holes on Mr. Alfred G. Paterson's station, "Yandil". These specimens vary in size from about 7.0 to $9.5 \mathrm{~mm}$., and in color from dark piceous to rufous with head and prothorax slightly darker. The elytral striae are all free at base in most specimens, but the basal end of the 5th stria is very close to that of the 6 th and occasionally the two are connected, leaving only 4 striae free at base. This is an example of the sort of variation, affecting Sloane's group characters, which has not yet been properly studied in most Australian Clivina, and which must be understood before the species can be finally arranged in natural groups. C. frenchi is apparently closely allied to C. obsoleta Sloane (and to the following new species), although Sloane put frenchi and obsoleta in different groups.

\section{Clivina diluta n. sp.}

Parallel, cylindrical, but not more slender than usual; head very large, neck wide; shining, head and prothorax piceous or castaneous, elytra more or less dilute brown; body below piceous or dark rufous, somewhat paler anteriorly; anterior legs rufous, antennae and middle and posterior legs brownish testaceous. Head $7 / 8$ or slightly less wide as prothorax (by measurement-to the eye, the head seems virtually as wide as prothorax); mandibles rather short; clypeus with middle part separated from wings, depressed, and rather strongly emarginate at middle, with 
angles of median part forming strong teeth; clypeal wings almost as prominent as teeth of median part, with outer angles narrowly rounded, separated from supra-antennal plates by distinct notches; eyes small, only slightly more prominent than supra-antennal plates, but not enclosed behind; 2 supra-orbital setae each side in all specimens; front not distinctly separated from clypeus, only slightly convex, with frontal sulci recurved; occiput without transverse impressed line; middle of front and usually sides and vertex also, but not occiput, closely punctate. Prothorax with lateral margins entire or nearly so, but in some specimens becoming vague or obsolete just before reaching basal margin; without longitudinal foveae on episterna; about as long as wide, with sides approximately parallel; front margin distinctly emarginate (as seen on a line perpendicular to pronotum); posterior angles broadly rounded; anterior angles acute except finely blunted (as usual) ; disc with median line fine, but distinct, anterior transverse impression more or less obsolete, sub-basal lateral impressions long, reaching to slightly in front of middle; surface of dise finely, sparsely punctulate and with a few irregular transverse strioles; posterior declivity vaguely rugose. Elytra parallel, hardly 1/20 wider than prothorax, truncate at base; 4 inner striae free at base, 5th united with 6 th; subhumeral carina short, not very distinct; striae almost entire, but vague or obliterated just before apex, punctulate; intervals nearly flat, 3rd with usual 4 distinct setigerous punctures on outer edge, surface of intervals with some fine, irregular, transverse strioles, but not distinctly punctulate. Prosternal process very narrow (attenuate) between anterior parts of coxae; prosternal episterna and lower surface of head and abdomen, especially at sides, with distinct isodiametric microsculpture; body virtually impunctate below. Anterior femora rather strongly lobed below; anterior tibiae each strongly 4-dentate externally, and with upper internal spine somewhat curved and thickened; middle tibiae each with a spur about $1 / 3$ from apex externally. Length about 6.3-7.0; width about $1.7 \mathrm{~mm}$.

Holotype (M. C. Z. Type No. 23,091) and 7 paratypes all from Wiluna and vicinity, Western Australia, most from 
Lake Violet but a few from "Yandil", Sept. 28-Oct. 3, 1931; from banks of ponds and water holes.

This new species is closely related probably only to Clivina obsoleta Sl. of Cape York (see Sloane's key, 1896, p. 162). The most important difference is probably in the form of the anterior angles of the prothorax. The prothorax is described as slightly narrowed anteriorly in obsoleta, with anterior margin truncate and anterior angles obtuse; while in diluta the prothorax is parallel, with anterior margin slighly emarginate and anterior angles somewhat acute except that, as usual in this genus, they are slightly blunted. Moreover, the head is probably much more closely punctate in diluta than in obsoleta, the front of the clypeus is emarginate at middle (described as truncate in obsoleta), and the description of obsoleta suggests other slight differences. I have not seen specimens of obsoleta. I believe that diluta is distinct from it, but the former may prove to be only a welldefined western subspecies of it rather than a separate species. The present new species, diluta, resembles $C$. frenchi Sl. (as obsoleta too is said to do) but is smaller, with a (short) subhumeral carina, relatively longer prothorax, and clypeus much more deeply emarginate at middle. These differences are not sexual, for dissection shows that I have both sexes of both species.

\section{Clivina wiluna $\mathrm{n}$. $\mathrm{sp}$.}

Parallel, cylindrical, head not unusually large; brown, darker (sometimes blackish) anteriorly. Head about 4/5 width prothorax; mandibles short; clypeus with middle part separated from wings, angles advanced and dentiform, clypeal wings angulate or sub-angulate externally, nearly as prominent as angles of median part, separated by distinct notches from supra-antennal plates; latter with outer angles somewhat variable in form but usually less (never more) prominent than angles of clypeal wings; eyes prominent, much more so than supra-antennal plates; front not distinctly separated from clypeus, more or less (variably) impressed at middle, frontal sulci recurved, front sparsely or not distinctly punctate, except punctation sometimes more distinct at middle. Prothorax slightly (1/20 or $1 / 10)$ 
longer than wide, slightly but distinctly narrowed anteriorly; anterior margin approximately truncate; posterior angles broadly rounded, anterior ones right or slightly obtuse, blunted; disc with middle line distinct, anterior transverse impression obsolete or nearly so, sub-basal lateral impression short and vague; surface of disc smooth except for a few transverse strioles. Elytra only $1 / 10$ or $1 / 20$ wider than prothorax, parallel, truncate at base; 4 inner striae free at base, 5 th united with 6 th; sub-humeral carina short, indistinct; striae entire except some very briefly obsolete at extreme apex, punctulate; intervals slightly convex, 3rd with usual 4 distinct setigerous punctures on outer edge. Prosternal process very narrow (attenuate) between anterior parts of coxae; prosternal episterna dull; body impunctate below. Anterior femora stout, lobed below; anterior tibiae 4-dentate externally, the upper tooth much shorter than the others but distinct and acute; upper internal spine of front tibia somewhat curved and thickened; middle tibia with spur about $1 / 3$ from apex externally. Length 5.7-6.4; width about $1.6 \mathrm{~mm}$.

Holotype (M. C. Z. Type No. 23,092) and 14 paratypes from Wiluna and vicinity, Western Australia, most at "Yandil" but 1 from Lake Violet, Sept. 28-Oct. 3, 1931; from the banks of ponds and water holes.

Apparently closely related only to Clivina cylindriformis Sl. from the Gulf of Carpentaria (see Sloane's key, 1896, p. 162). The most important differences are that the front femur of wiluna is 4-dentate externally (described as 3dentate in cylindriformis) and that in wiluna the clypeal wings are angulate and at least as prominent as and usually more prominent than the angles of the supra-antennal plates (clypeal wings described as rounded and apparently much less prominent than the angles of the supra-antennal plates in cylindriformis). As compared with the description of cylindriformis, wiluna evidently also has the median part of the clypeus with more prominent angles, the front much less punctate, and the color paler; and the prosternum is usually not sulcate across the base in wiluna, although this is not a trustworthy character. I have not seen specimens of cylindriformis. From C. obsoleta Sl., to which 
wiluna might be run in Sloane's key, wiluna differs in having a much smaller head, with relatively more prominent eyes.

\section{Clivina suturalis Putz.}

As Sloane has pointed out (1920, p. 122), verticalis Putz. and dorsalis Blackb. seem to be synonyms of this species. The species is extremely variable in color. A long series from Rottnest Island (near Perth), Western Australia, taken in October, 1931, varies from elytra testaceous with the sutural region only slightly reddish (these specimens possibly slightly immature) to black with only a short reddish dash behind the humerus, the dash not reaching the middle of the elytral length, and all stages of intermediates occur.

\section{Clivina grata n. sp.}

Of about average stoutness for Clivina, convex but not cylindrical; color either entirely rufous or rufous with elytra piceous black and lower surface posteriorly rufopiceous; surface above moderately shining. Head $3 / 4$ or a trifle less width prothorax; mandibles rather short but acute; clypeus with median part evenly slightly emarginate, separated from wings by indistinct, very obtuse notches; eyes small, enclosed behind by convex genae about as long as eyes and nearly as prominent; front not distinctly separated from clypeus, slightly convex between broad facial sulci; vertex slightly impressed at middle; vertex and front, but not clypeus, rather closely punctate. Prothorax $1 / 10$ (slightly \pm ) longer than wide, widest about $1 / 3$ from base, thence slightly narrowed anteriorly; posterior angles broadly rounded, finely denticulate, anterior angles minutely prominent; disc with median line and apical transverse line distinct, surface of disc entirely covered with fine, rather irregular punctation. Elytra $1 / 6$ or $1 / 7$ wider than prothorax, elongate oval rather than parallel, with humeri slightly narrowed; 3 inner striae free at base, 4 th united with external striae; subhumeral carinae distinct; striae entire except partly obliterated at extreme apex, impressed and punctate on disc; discal striae convex, 3rd with 4 distinct setigerous punctures on outer edge. Prosternum 
transversely sulcate in front, prosternal process very fine (attenuate) opposite front margins of coxae; prosternal episterna closely rugulose; indistinct traces of punctation at sides of prosternum (not on episterna) ; hind body below roughened at sides but not distinctly punctate. Inner wings reduced to narrow strips about $1 / 2$ length of elytra; metepisterna shortened. Anterior femur with lower, posterior margin approximately straight (faintly convex) as seen from behind; anterior tibia externally with three long teeth and (above them) a small triangular projection; middle tibia with a slender spur $1 / 3$ or $1 / 4$ from apex. Length $5 \mathrm{~mm}$. (or slightly less) ; width about $1.4 \mathrm{~mm}$.

Holotype (M. C. Z. No. 23,093) and 2 paratypes all from near the town of Margaret River, southwestern division of Western Australia, October, 1931.

This species finds its closest relatives in the Heterogena Group of Clivina. In Sloane's second key (1904, p. 714) it would go with olliffi Sl. and blackburni Sl., differing from the former by being smaller and with narrower prothorax, and from the latter by having a distinct anterior transverse line on the pronotum. So far as I can judge from the descriptions alone, there are many other differences too. The separation of the median part of the clypeus from the clypeal wings in grata is so slight that the species might easily be referred to the Australasiae Group, where it would run (in Sloane's key, 1904, p. 719) to ferruginea or to nigra or occulta, but it probably is not really very closely related to any of these.

In my opinion, this new species (grata) really represents some stock close to heterogena Putz., modified as a result of reduction of the wings. The other characters which distinguish grata, especially the more oval elytra and shortened metepisterna, often accompany or follow wingreduction among Carabidae (cf. Darlington 1936) and occur in some other (unrelated) flightless Australian Clivina, especially in the Procera Group. Even the reduced eyes of grata may be a secondary result of wing atrophy. I took, also at Margaret River, a single specimen of a Clivina which may represent the winged stock from which grata has been derived. It is bicolored like some examples 
of grata and is similar also in many ways structurally, but it is fully winged, with elytra parallel-sided, metepisterna long, and eyes relatively large. In these respects it is very close to heterogena, of which we have a series from Victoria. However, the Margaret River specimen differs from both heterogena and the present new species (grata) in having the abdomen rugose-punctate, most strongly so on the apical segment. The differences between this specimen and grata seem too great for them to be forms of a single dimorphic species. This specimen very likely represents a new species, but I do not care to describe it without more material.

\section{Clivina sculpticeps n. sp.}

Rather broad, subparallel, only moderately convex; rufous, not very shining. Head about $7 / 10$ width prothorax; mandibles short; clypeus with marginal outline as in australasiae and its immediate allies, broadly emarginate at middle, with median part not at all separated from wings; latter rounded, separated from supra-ocular plates by obtuse notches; eyes prominent; front separated from clypeus by a deep and conspicuous transverse impression, and clypeus before impression with a broad more or less semicircular swelling; front and usually vertex somewhat variably longitudinally impressed at middle, and usually also with oblique irregular impressions at sides; frontal sulci long, recurved; front impunctate or virtually so; occiput with a few punctures at sides. Prothorax as wide as long or barely wider, moderately narrowed anteriorly; posterior angles broadly rounded, slightly dentate; anterior angles also rounded, but more narrowly so; dise with median and anterior transverse lines distinct, sub-basal lateral impressions faint or obsolete; surface of disc impunctate, with a few transverse strioles. Elytra about $1 / 10$ wider than prothorax, only slightly narrowed anteriorly, with base subtruncate; humeri distinct, rather narrowly rounded; only 3 striae free at base; sub-humeral carinae well developed; striae entire, moderately impressed (less so apically), punctulate; intervals convex, 3rd 4-punctate as usual. Prosternum more or less sulcate transversely anteriorly, with episterna striolate and rugulose, not punctate; 
prosternal process narrow but not "attenuate" between anterior parts of coxae; body below locally rugulose but not punctate. Anterior femora with lower posterior margin slightly convex; anterior tibiae strongly 3-dentate; middle tibia with a strong spur about $1 / 4$, from apex externally. Length 7.8-9.0; width 2.2-2.5 mm.

Holotype (M. C. Z. Type No. 23,094) and 4 paratypes all from Geraldton, Western Australia, October, 1931. Also 1 specimen, not a type, measuring only 6.5 by $1.8 \mathrm{~mm}$., from Meekatharra, Western Australia (nearly 300 miles inland from Geraldton), Sept. 25, 1931.

The form of the clypeal margin and the distinct joining of the 4th and 5th elytral striae at base put this new species in Sloane's Australasiae Group. In Sloane's second key (1904, p. 719) it actually runs to australasiae and the latter's close relatives lepida Putz. and dingo Sl., but the new species (sculpticeps) differs from all of them by the conspicuous and rather complex sculpture of the head. The brown rather than black coloration is probably also a distinguishing character of sculpticeps, but a relatively unimportant one.

DARIINGTON, P. J. JR.

\section{REFERENCES}

1936. Variation and atrophy of flying wings of some carabid beetles. Ann. Ent. Soc. America, 29:136-176, pls. I-III.

SLOANE, T. G.

1896. On the Australian Clivinides. Proc. Linn. Soc. New South Wales, 21:143-257, 275-280.

1904. Revisional notes . . . . . Clivinini. Ibid., 29:710-733.

1905. [Check-list of Clivina.] Ibid., 30 Suppl.: 4-8.

1907. [New Clivina.] Ibid., 32:346-350.

1916. [New Clivina.] Ibid., 41:600-607.

1917. [New Clivina.] Ibid., 42:406.

1920. [Tasmanian Clivina.] Ibid., 45:122-123.

1923. [New Clivina.] Ibid., 48:18-19. 

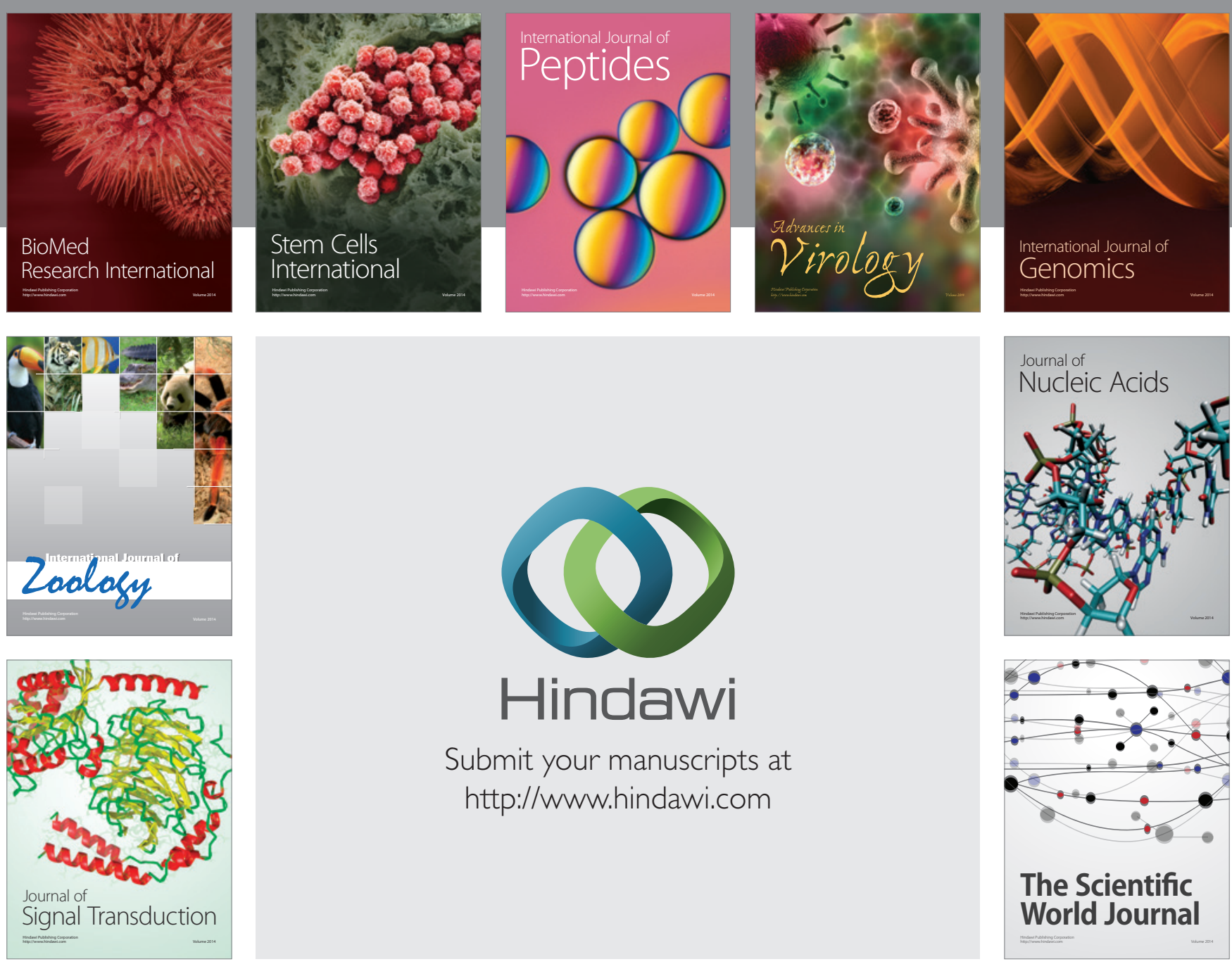

Submit your manuscripts at

http://www.hindawi.com
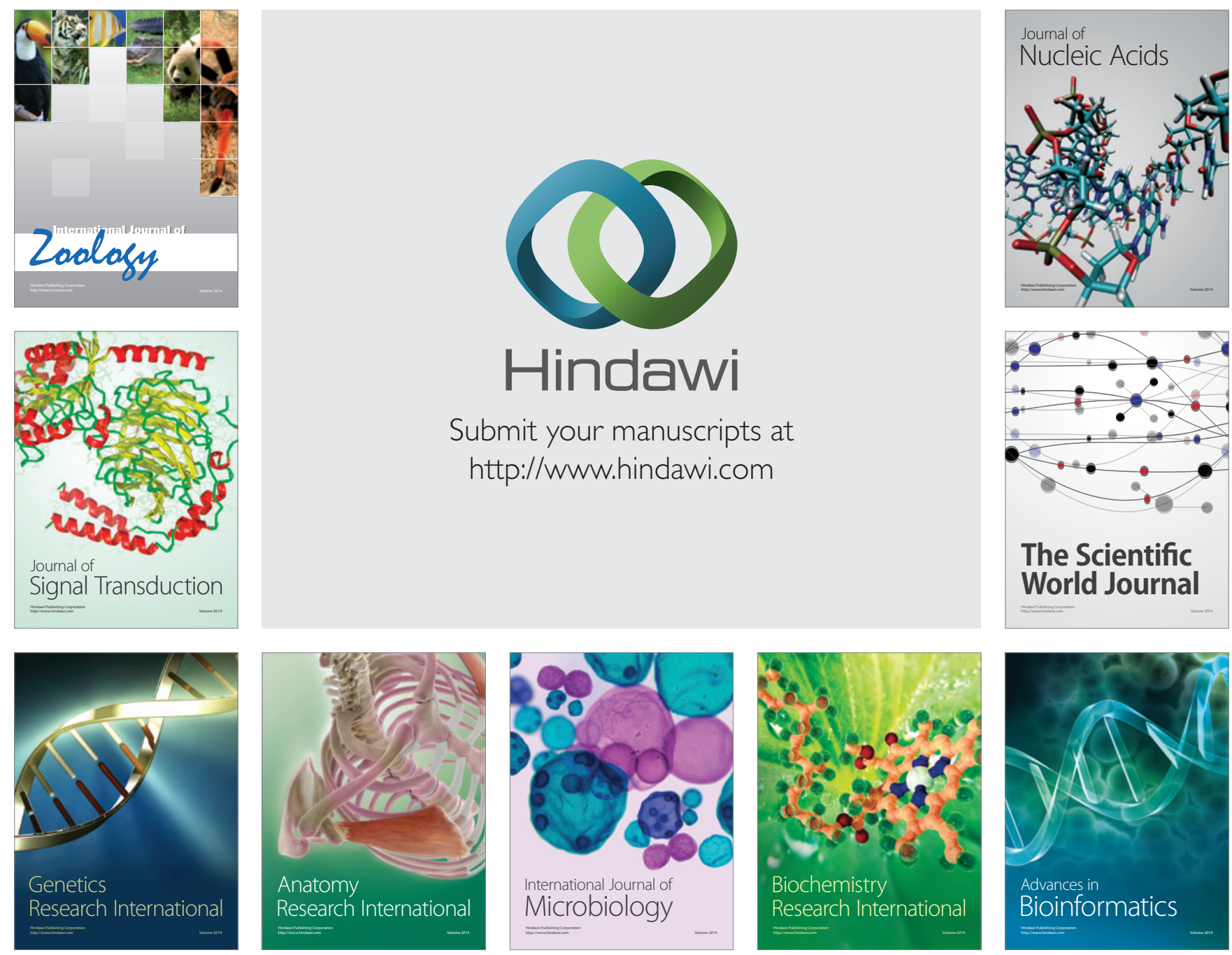

The Scientific World Journal
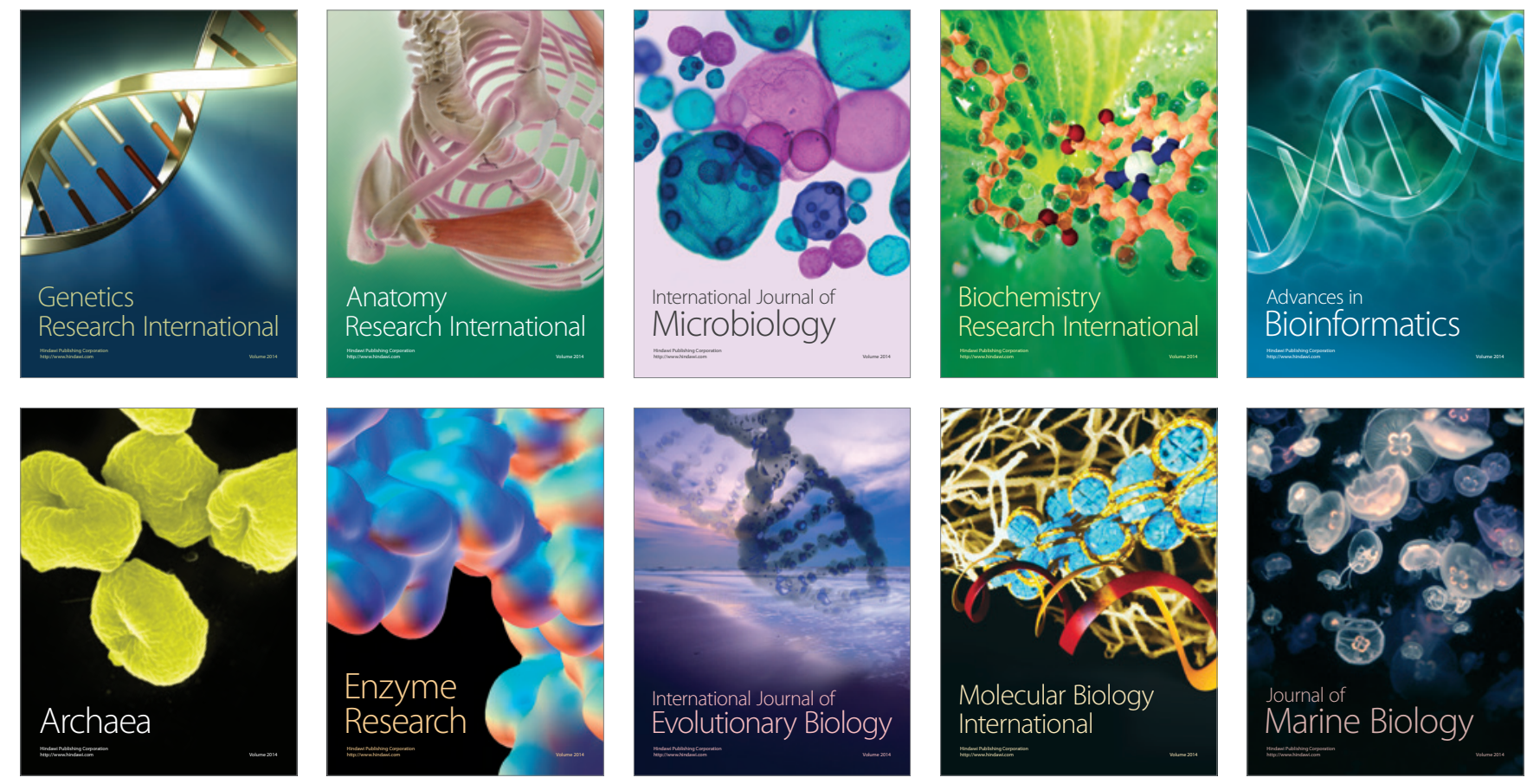